\title{
Variabilidade espacial do banco de sementes em área de Caatinga no Nordeste do Brasil
}

\author{
Space variability of the seed bank in area of Caatinga in the Northeastern region \\ of Brazil
}

\section{Angeline Maria da Silva Santosi, Riselane de Lucena Alcântara Bruno ${ }^{\mathrm{II}}$, José de Oliveira Cruz ${ }^{\text {III }}$, Ivandro de França da Silva ${ }^{\mathrm{IV}}$, Alberício Pereira de Andradev}

\begin{abstract}
Resumo
O banco de sementes no solo é uma das principais estratégias de sobrevivência em longo prazo das comunidades vegetais diante da sazonalidade e da irregularidade do regime pluviométrico em áreas áridas e semiáridas. Considerando a forte variação na riqueza e a densidade do banco de sementes nesses ambientes, este estudo tem como objetivo avaliar a variação espacial do banco de sementes em uma área de Caatinga, no Nordeste do Brasil, determinando a sua composição florística e densidade de germinação. A área selecionada foi uma lagoa temporária no Cariri paraibano, com vegetação altamente antropizada, devido a diversos usos ao longo do tempo. Em cada ponto cardeal, tomando como referência o centro da lagoa, foram retiradas amostras de solo para o banco de sementes. Todo o material coletado foi distribuído em bandejas plásticas e irrigado diariamente. A determinação da densidade de sementes no banco do solo foi realizada pelo método de emergência de plântulas e expressa em sementes. $\mathrm{m}^{-2}$. A flora do banco de sementes do solo da Caatinga foi representada neste estudo por 26 espécies e três morfoespécies, distribuídas em 11 famílias e 26 gêneros, dentre elas as famílias Poaceae e Asteraceae, com maior número de espécies. A principal forma de vida do banco de sementes foi herbácea e a densidade média da área de estudo foi de 2.942 sementes. $\mathrm{m}^{-2}$ (lagoa) e 3.826 sementes. $\mathrm{m}^{-2}$ (no entorno) e após o estresse hídrico foi de 732 sementes. $\mathrm{m}^{-2}$ e 1.208 sementes. $\mathrm{m}^{-2}$, nas áreas da lagoa e do seu entorno, respectivamente. A área do entorno da lagoa apresenta a maior densidade de plantas por $\mathrm{m}^{2}$ e maior diversidade de espécies. Além disso, o sentido Norte, em ambas as áreas, apresentou menor densidade de sementes. $\mathrm{m}^{-2}$.
\end{abstract}

Palavras-chave: Caatinga; Estrato herbáceo; Lagoa temporária; Riqueza de espécies; Semiárido

\footnotetext{
Engenheira Florestal, Dra., Pós-Doutoranda (PNPD/CAPES), Programa de Pós-Graduação em Agronomia, Universidade Federal da Paraíba, Campus II, Rod. PB 079 - Km 12, Caixa Postal 66, CEP 58397-000, Areia (PB), Brasil. angelinemssantos@gmail.com (ORCID: 0000-0001-8765-8291) Engenheira Agrônoma, Dra., Professora Aposentada do Departamento Fitotecnia e Ciências Ambientais, Universidade Federal da Paraíba, Centro de Ciências Agrárias, Rodovia PB-079, Km 12, Cx. Postal 66, 58397-000, Areia (PB), Brasil. lane@cca.ufpb.br (ORCID: 0000-0002-4206-6417)

III Agrônomo, MSc., Doutorando em Agronomia, Universidade de Brasília, Asa Norte, CEP 70910900, Brasília (DF), Brasil. lucildoagronomia@gmail. com (ORCID: 0000-0002-8283-5671

IV Agrônomo, Dr., Professor Associado Aposentado do Departamento de Solos e Engenharia Rural, Universidade Federal da Paraíba, Campus II, Rod. PB 079 - Km 12, Caixa Postal 66, CEP 58397-000, Areia (PB), Brasil. ivandrofranca@gmail.com (ORCID: 0000-0003-1574-1664

Agrônomo, Dr., Professor da Unidade Acadêmica de Garanhuns, Universidade Federal Rural de Pernambuco, Avenida Bom Pastor, Boa Vista, CEP 55292-270, Garanhuns (PE), Brasil. albericio@uol.com.br (ORCID: 0000-0002-1223-394X)
} 


\begin{abstract}
The seed bank in soil is one of the main long-term survival strategies of plant communities in the view of seasonality and irregularity of rainfall in arid and semiarid areas. Considering strong variation in seed bank richness and density in these environments, this study aims to evaluate the spatial variation of seed bank in an area of Caatinga, in northeastern Brazil, determining its floristic composition and germination density. The selected area was a temporary lagoon in the Cariri region of Paraíba state, with highly anthropized vegetation, due to various uses over time. At each cardinal point, taking the center of the lagoon as a reference, soil samples were taken from the seed bank. All material collected was distributed in plastic trays and irrigated daily. The determination of seed density in the soil bank was performed by the seedling emergence method and expressed in seeds. $\mathrm{m}^{2}$. The flora of the Caatinga soil seed bank was represented in this study by 26 species and three morphospecies, distributed in 11 families and 26 genera, among them the Poaceae and Asteraceae families with the largest number of species. The main life form of the seed bank was herbaceous and the average density of the study area was 2,942 seeds.m-2 (lagoon) and 3,826 seeds.m-2 (in the surroundings) and after water stress was 732 seeds.m-2 and 1,208 seeds.m-2, in and around the lagoon areas, respectively. The area surrounding the lagoon has the highest plant density per $\mathrm{m}^{2}$ and the highest diversity of species. In addition, the northern direction in both areas presented lower seed density.
\end{abstract}

Keywords: Caatinga; Herbaceous stratum; Temporary lagoon; Species richness; Semiarid

\title{
Introdução
}

O banco de sementes no solo é composto por todas as sementes viáveis encontradas em sua superfície, associadas à serapilheira ou enterradas no solo numa determinada área num dado momento (WALCK et al., 2005). A composição de bancos de sementes é classificada como temporária ou persistente, dependendo da regeneração da vegetação durante as épocas do ano. Dessa forma, as plantas diferem na duração em que suas sementes permanecem no solo, dentro de uma mesma espécie, havendo variabilidade no tempo que passam no banco de sementes do solo (SAATKAMP; POSCHLOD; VENABLE, 2014).

O conhecimento sobre a composição do banco de sementes do solo nos dá informações sobre densidade, composição florística e viabilidade de sementes que compõem o banco (FIGLIOLIA; FRANCO; BIRUEL, 2004), além de ser eficiente na regeneração de clareiras, bordas de matas e áreas desmatadas (ARAÚJO et al., 2001). Segundo Gasparino et al. (2006), a composição florística é afetada pelos tipos de dispersão das espécies na área e a dispersão adotada pelas espécies do entorno, promovendo um sistema dinâmico de entradas (provenientes da chuva de sementes) e saídas (que podem ocorrer por respostas fisiológicas, alterações ambientais, como mudanças na radiação, temperatura e umidade, além da predação das sementes e perda de viabilidade).

Em regiões áridas e semiáridas, os bancos de sementes no solo constituem-se numa das principais estratégias de sobrevivência em longo prazo das comunidades vegetais diante da sazonalidade e irregularidade do regime pluviométrico (BASKIN; NAN; BASKIN, 1998). No entanto, pouco se sabe sobre o papel do banco de sementes como estratégia de sobrevivência das espécies da Caatinga, principalmente as anuais. Essas estratégias estão relacionadas aos diferentes tipos de dormência e germinação das sementes das populações que compõem a comunidade, onde se observa que no início das chuvas há uma alta velocidade de rebrotamento das espécies e grande quantidade de germinação (BASKIN; NAN; BASKIN, 1998).

A Caatinga ocupa a maior parte do Nordeste do Brasil é coberta por uma vegetação xerófila, com fisionomia e florística variadas (RODAL; SAMPAIO; FIGUEREDO, 2013), sendo constituída por um mosaico de espécies herbáceas, arbustivas, arbóreas e cactáceas. As espécies desse bioma são adaptadas à condições ambientais severas como irregularidade da distribuição das chuvas, alta radiação solar e altas temperaturas, baixa umidade relativa, elevada evapotranspiração, além de apresentam peculiaridades nas formas de vegetação, sendo as adaptações climáticas e os mecanismos de absorção e retenção de água nos solos os principais fatores que contribuem para 
essas especificidades nas comunidades vegetais. A riqueza de espécies herbáceas na Caatinga chega a ser três vezes maior que a riqueza de espécies lenhosas, tais características que a tornam um bom exemplo para monitorar a influência do clima e dos micro-habitats sobre a dinâmica regenerativa (ARAÚJO; CASTRO, ALBUQUERQUE,2007).

Num estudo realizado na região de Caatinga, no Nordeste brasileiro, Silva (2009) observou que as diferenças sazonais nem sempre influenciam a densidade de sementes e a riqueza de espécies do banco de sementes. Esse fato se deve aos pulsos de precipitação que possam ocorrer na estação seca, impulsionando uma germinação das sementes acumuladas de anos anteriores, proporcionando assim uma redução na densidade de sementes num determinado momento. No entanto, Santos et al. (2013) ressaltam que as interações micro-habitat x alterações climáticas podem promover a sobrevivência e manutenção das populações de plantas em ambientes áridos.

Os métodos de quantificação do número de sementes do banco do solo são bastante diversificados. O método de emergência de plântulas, em que as amostras são distribuídas em bandejas na casa de vegetação, é comumente utilizado (COSTA; ARAÚJO, 2003; KELLERMAN; VAN ROOYEN, 2007; MAMEDE; ARAÚJO, 2008), mas apresenta algumas limitações. Em áreas de Caatinga, estudos que investigam a densidade de sementes e riqueza de espécies no banco de sementes do solo são restritos, destacando-se Costa e Araújo (2003), Silva (2009), Santos et al. (2010), Parente et al. (2011), Santos et al. (2013), Ferreira et al. (2014), Ribeiro et al. (2017) e Sousa et al. (2017). Diante do exposto, este trabalho tem como objetivo avaliar a variação espacial do banco de sementes em uma área de Caatinga no Nordeste do Brasil, determinando a densidade de germinação e sua composição florística.

\section{Material e métodos}

\section{Caracterização da área de estudo}

As amostras de solo para a composição do banco de sementes foram coletadas na Estação Experimental do Centro de Ciências Agrárias da UFPB, localizada no município de São João do Cariri-PB, Mesorregião da Borborema e Microrregião do Cariri Oriental, situado nas coordenadas $7^{\circ} 22^{\prime} 45,1^{\prime \prime}$ e e $36^{\circ} 31^{\prime} 47,2$ ”'W, com elevação variando entre $400 \mathrm{~m}$ e $600 \mathrm{~m}$. A área de estudo apresenta um relevo suave ondulado e faz parte da Bacia Hidrográfica do Rio Paraíba, (Sub-bacia do rio Taperoá e Microbacia do Rio Taperoá). Os principais tipos de solos encontrados na Estação Experimental são: Luvissolo Crômico Vértico, Vertissolo e Neossolo Litólico.

A vegetação é caracterizada como Caatinga hiperxerófila, decorrente do tipo climático que envolve a região, Bsh - semiárido quente com chuvas de verão, segundo a classificação de Köppen e um bioclima do tipo $2 \mathrm{~b}$ ( 9 a 11 meses secos) - subdesértico quente de tendência tropical, mediante classificação de Gaussen. A precipitação média é de $400 \mathrm{~mm} /$ ano e variabilidade de $84 \mathrm{e}$ $93 \mathrm{~mm} /$ ano. A umidade relativa é de aproximadamente $70 \%$ e a evapotranspiração é de $2.000 \mathrm{~mm} /$ ano (SUPERINTENDÊNCIA DE ADMINISTRAÇÃO DO MEIO AMBIENTE, 2004).

\section{Coleta das amostras de solo para o banco de sementes}

A área selecionada para coleta do banco de sementes corresponde a uma lagoa temporária, com vegetação de Caatinga com diferentes condições de conservação, onde há o pastejo efetivo e houve pastejo eventual de caprinos e ovinos. Em geral, a área apresenta fisionomia caracterizada por arbustos e árvores de pequeno porte e bastante alterada devido aos diversos usos ao longo do tempo (plantio de algodão e retirada de lenha), além do componente herbáceo principalmente no período chuvoso. Devido à irregularidade das chuvas, a água da lagoa varia de acordo com as épocas chuvosa e seca.

Para caracterizar a densidade e a composição do banco de sementes do solo foram coletadas 
amostras com uma estrutura de ferro vazada, com dimensão de $0,50 \mathrm{~m} \times 0,50 \mathrm{~m}$ e profundidade de $5 \mathrm{~cm}$. A estrutura foi situada sobre a superfície do solo permitindo a padronização da área, incluindo a serapilheira. Tomando por base o centro da lagoa, foi coletado em cada ponto cardeal seis amostras de solo dentro da lagoa temporária e cinco no seu entorno, equidistantes (a cada $5 \mathrm{~m}$ ), totalizando 24 e 20 amostras, respectivamente. Em seguida, foram acondicionadas em bandejas plásticas (com dimensões de $28 \mathrm{~cm}$ x $42 \mathrm{~cm} \times 7 \mathrm{~cm}$ ), devidamente etiquetadas e conduzidas a casa de vegetação ao Laboratório de Análises de Sementes no Centro de Ciências Agrárias/ UFPB, para a implantação do método de emergência de plântulas. Além disso, coletou-se material para fazer as análises químicas e físicas do solo (Tabela 1) das duas áreas experimentais com profundidade de aproximadamente $20 \mathrm{~cm}$, as quais foram conduzidas ao Laboratório de Análise de Solos e Água do CCA da UFPB.

Tabela 1 - Análise físico-química dos solos das áreas da lagoa e entorno, situadas na Estação Experimental em São João do Cariri-PB

Table 1 - Physical and chemical analysis of the soils of the lagoon and its surroundings areas, located at the Experimental Station in São João do Cariri, PB state

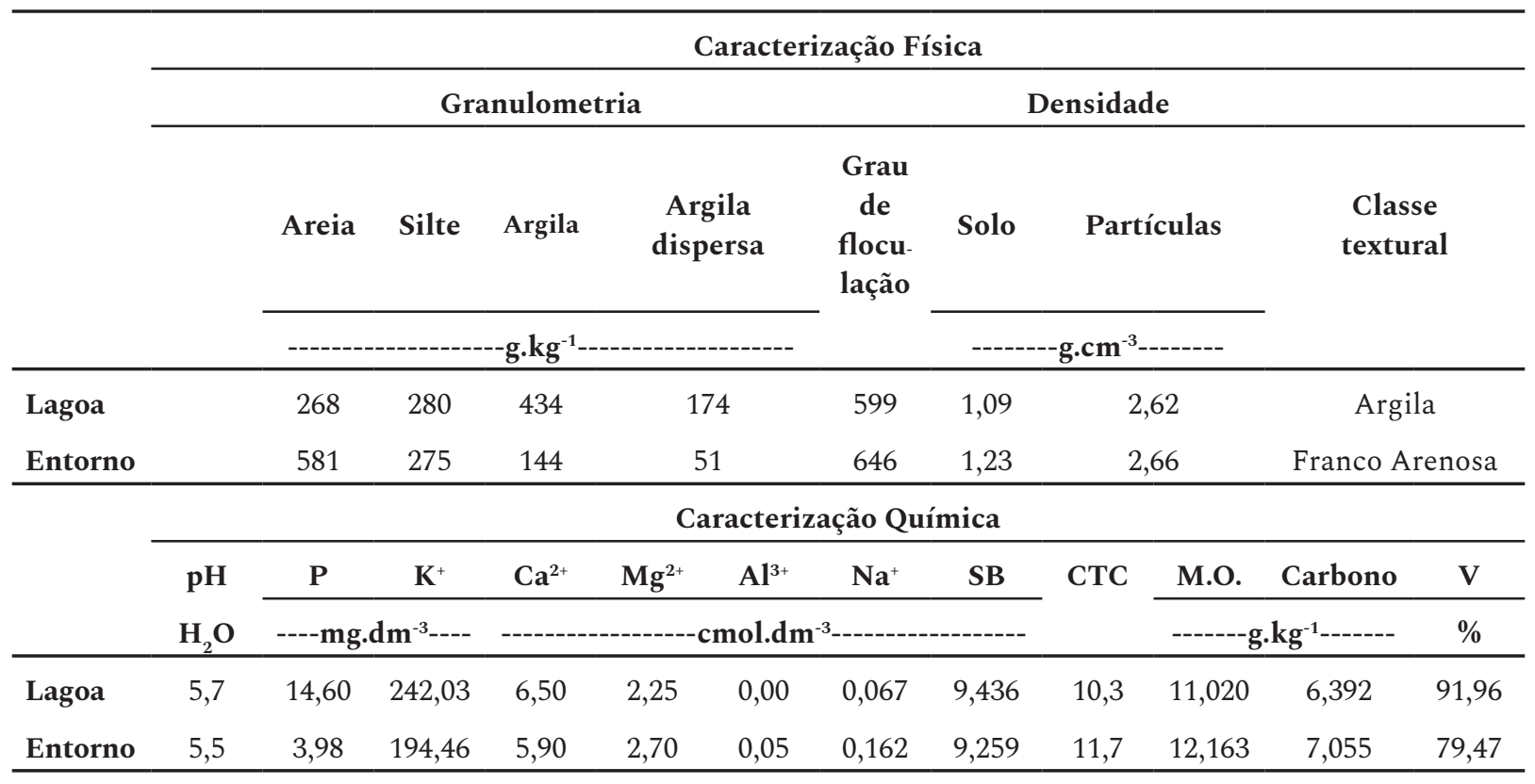

Fonte: Autores (2019)

Em que: $\mathrm{pH}$ = potencial Hidrogeniônico; $\mathrm{P}$ = Fósforo; $\mathrm{K}$ = Potássio; $\mathrm{Ca}=$ Cálcio; $\mathrm{Mg}$ = Magnésio; $\mathrm{Al}=\mathrm{Alumínio} ; \mathrm{Na}=$ Sódio; SB = Soma de Bases; CTC = Capacidade de Troca de Cátions; M.O. = Matéria Orgânica; V = Saturação por Bases.

\section{Implantação, caracterização do banco de sementes e análise dos dados}

Na casa de vegetação, as amostras foram irrigadas diariamente para manutenção de $80 \%$ da capacidade de campo do solo (Figura 1a, 1b). Dessa forma, acompanhou-se o crescimento das plântulas emergentes para quantificação e identificação taxonômica realizada por meio da literatura. As espécies foram organizadas nas famílias conforme classificação da Flora do Brasil 2020, em construção (JARDIM BOTÂNICO DO RIO DE JANEIRO, 2020). A determinação da densidade de sementes no banco do solo foi realizada pelo método de emergência de plântulas e expressa em sementes. $\mathrm{m}^{-2}$. 
Figura 1 - (a) Pesagem das bandejas para irrigação; (b) Bandejas irrigadas mantendo 80\% da capacidade de campo no banco de sementes do solo

Figure 1 - (a) The weighing of irrigation trays; (b) Irrigated trays irrigation maintaining $80 \%$ of the field capacity in the soil seed bank

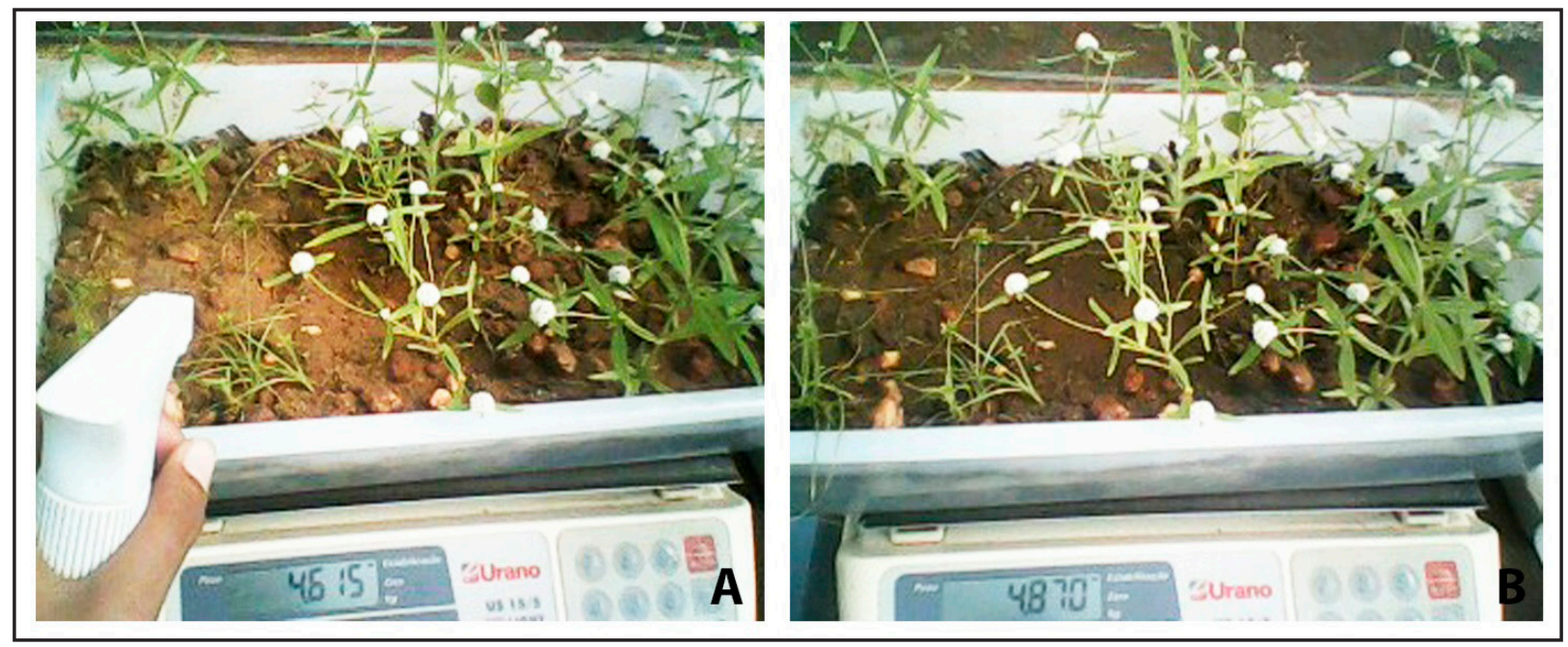

Fonte: Autores (2019)

Após 185 dias do início do experimento, interrompeu-se a irrigação durante 14 dias e o solo foi revolvido para facilitar a germinação das sementes da camada inferior. Ressalta-se que o período determinado para começar o período de estresse hídrico foi quando não havia mais nenhuma plântula emergindo. Depois desse período, voltou-se a irrigar por mais 61 dias. Esse estresse hídrico teve a finalidade de simular a condição da estação seca que ocorre no campo, podendo proporcionar a germinação de sementes que apresentassem algum tipo de dormência e daquelas que se encontravam nas camadas mais profundas do solo.

A análise estatística foi realizada através do Programa Estatístico SAS ${ }^{\oplus}$. O efeito do tempo, na densidade de sementes germinadas, foi analisado pelo teste $\chi^{2}$ (Qui-Quadrado) com 5\% de significância. Além disso, construíram-se gráficos de isolinhas para identificar a semelhança do número de sementes $/ \mathrm{m}^{2}$ entre a área da lagoa e o seu entorno, em relação aos pontos cardeais através do software Surfer ${ }^{\circledast} 8.0$.

\section{Resultados e discussão}

\section{Composição florística do banco de sementes}

A flora do banco de sementes do solo da Caatinga paraibana foi representada neste estudo por 26 espécies e três morfoespécies (não identificadas em nível de espécie) distribuídas em 11 famílias e 26 gêneros (Figura 2, Tabela 2). Os gêneros Eragrostis Wolf (Poaceae), Emilia Cass (Asteraceae) e Sida L. (Malvaceae) foram os que mais se destacaram em relação ao número de espécies. Poaceae foi a família com maior riqueza de espécies no banco de sementes do solo sendo representada por sete espécies. Em estudos realizados em áreas de Caatinga no Quixadá - CE, Costa e Araújo (2003) observaram que as famílias com maior riqueza de espécies foram Poaceae, Euphorbiaceae e Convolvulaceae. Santos et al. (2010), ao analisarem a composição florística do banco de sementes em floresta tropical seca (Caatinga) em Caruaru - PE, identificaram 18 famílias, dentre elas Poaceae e Portulacaceae, esta com o maior número de espécies. 


\section{Figura 2 - Número de espécies por família encontradas no banco de sementes do solo na} Caatinga

Figure 2 - Number of species per family found in the soil seed bank in Caatinga

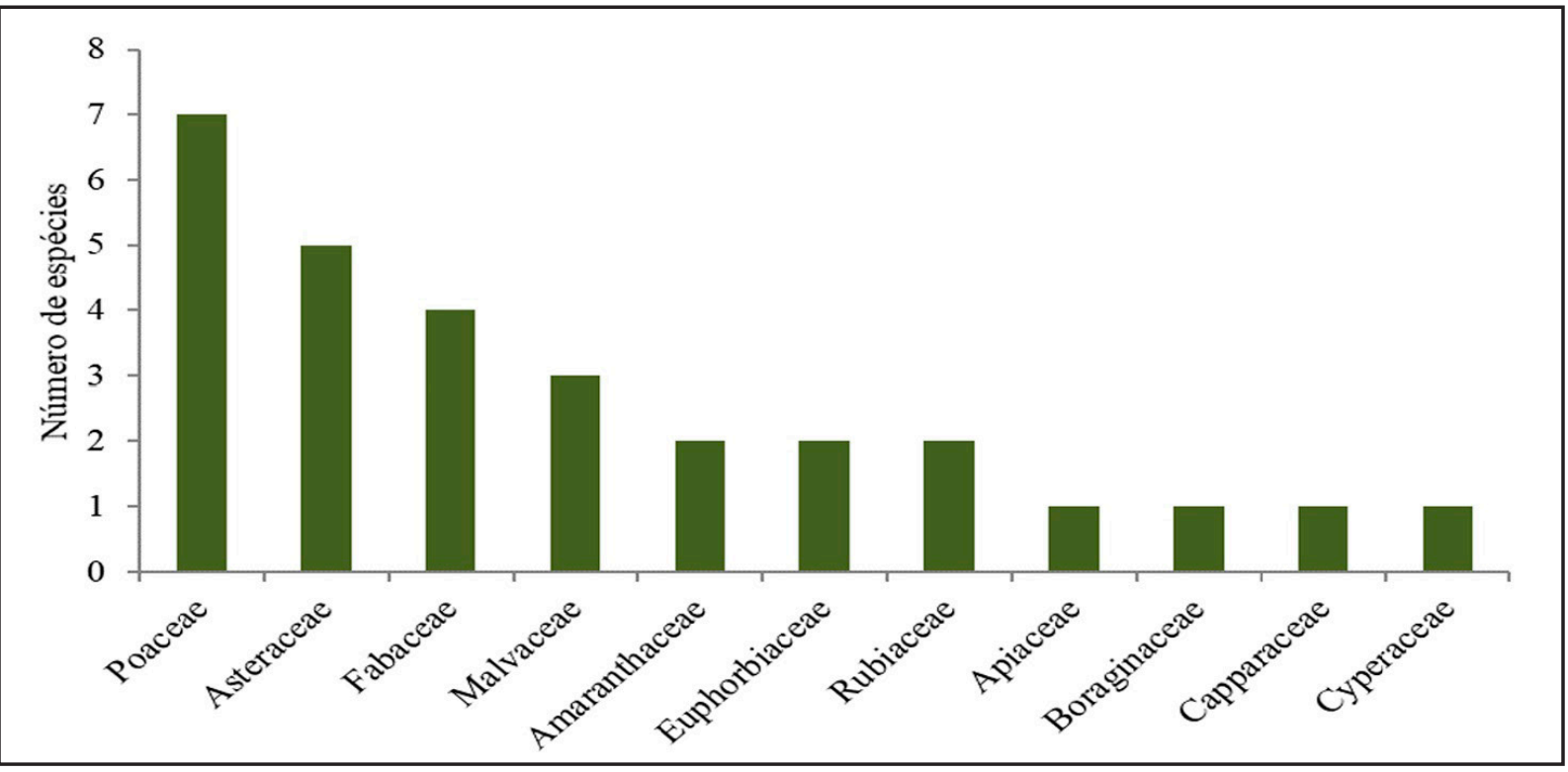

Fonte: Autores (2019)

As espécies da família Amaranthaceae, Emilia fosbergii(Asteraceae), Chloris barbata, Eragrostis ciliaris e Paspalum scutatum (Poaceae) foram encontradas em ambas as áreas de coleta, na lagoa e no seu entorno. Após os 14 dias de estresse hídrico, quando voltou a fazer as irrigações diárias, apenas uma morfoespécie emergiu no banco de sementes do solo, Eryngium da família Apiaceae na área da Lagoa. Como as espécies de um banco de sementes não tem uniformidade de germinação, possivelmente essa espécie só germinou quando encontrou as condições favoráveis. Com relação à espécie Emilia sonchifolia, esta pode ter sido introduzida na área, haja vista que não é comum encontrá-la em levantamentos realizados na Caatinga.

Tabela 2 - Lista das famílias, espécies, forma de vida e área registradas no banco de sementes do solo em área de Caatinga

Table 2 - List of families, species, life form and area recorded in the soil seed bank in the Caatinga area

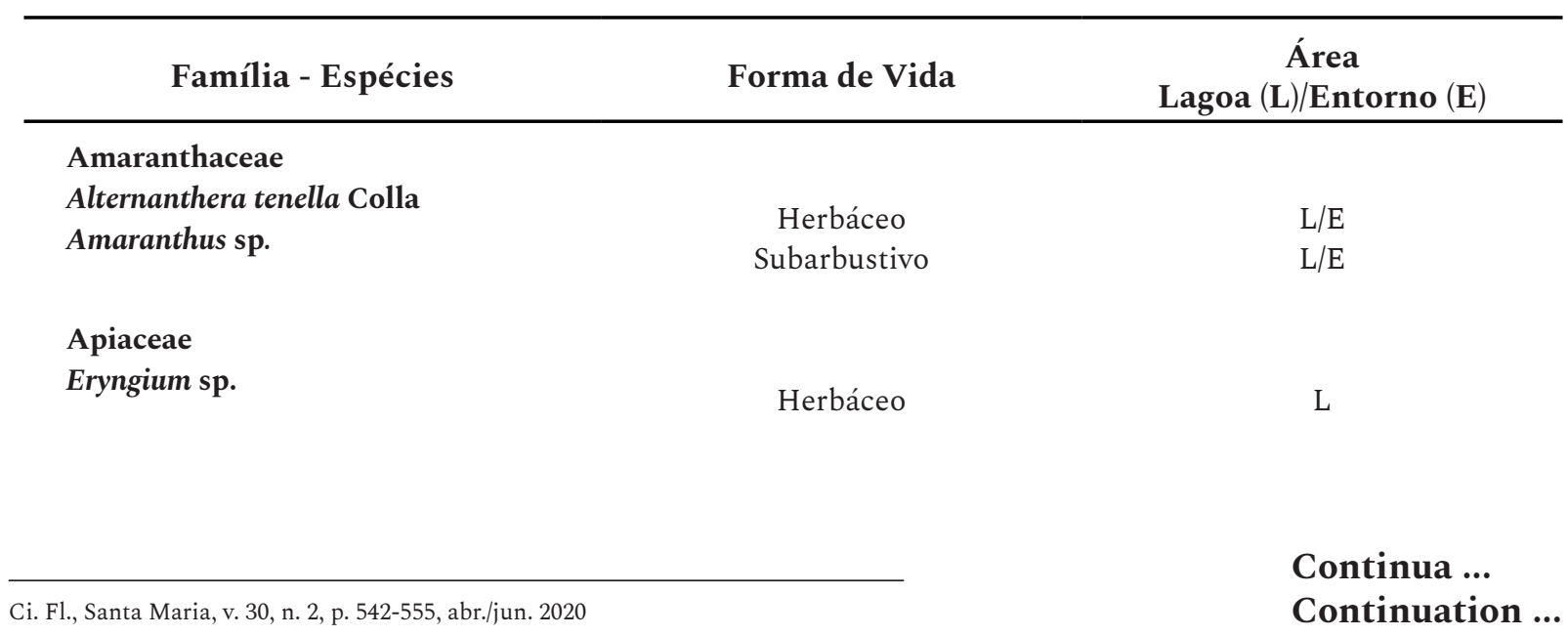


Tabela 2 - Conclusão ...

Table 2 - Conclusion ...

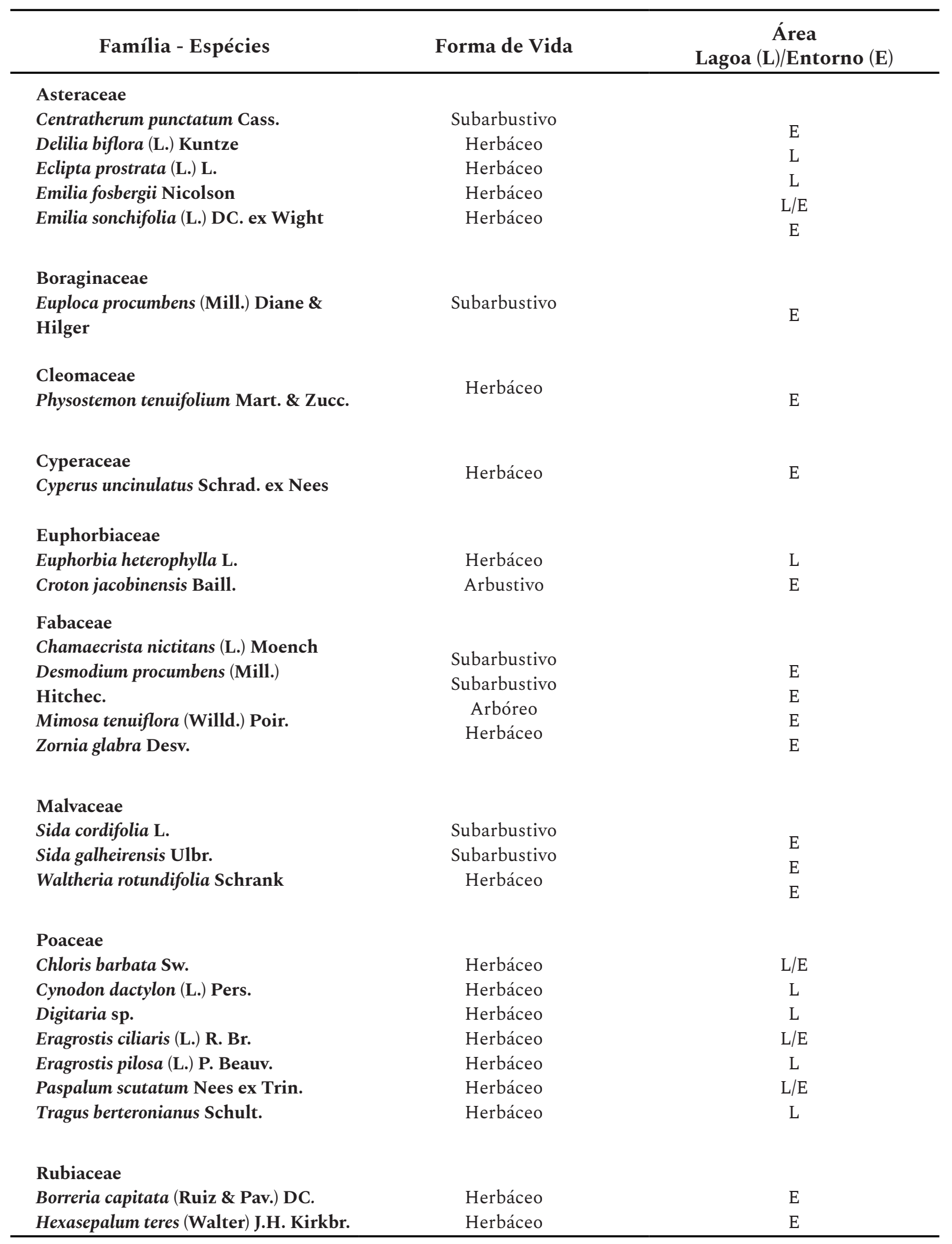

Fonte: Autores (2019) 
As formas de vida predominantes na área estudada foram herbáceas (18 espécies e duas morfoespécies), subarbustiva (seis espécies, uma morfoespécie), arbustiva (uma espécie, Croton jacobinensis) e arbórea (uma espécie, Mimosa tenuiflora). As espécies de C. jacobinensis e M. tenuiflora foram encontradas na flora do banco de sementes da área do entorno da lagoa temporária. A predominância de espécies herbáceas e a reduzida contribuição de espécies lenhosas no banco de sementes também foram relatados por outros autores que realizaram estudos em regiões áridas (GUO; RUNDEL; GOODALL, 1998) e semiáridas (COSTA; ARAÚJO 2003; FIGUEROA; TEILLIER; JAKSIC, 2004; MAMEDE; ARAÚJO, 2008; SANTOS et al., 2010; RIBEIRO et al., 2017). Como a maioria das espécies nessas regiões são anuais, essa maior riqueza pode ser justificada. Além disso, as herbáceas anuais, por completarem seu ciclo de vida em um curto período e posteriormente liberarem suas sementes, mantêm a renovação do estoque de suas sementes no solo, garantindo sua ocupação na área (COSTA; ARAÚJO 2003).

A predominância de uma determinada forma de vida num ambiente depende, principalmente, do tipo de pressão sofrida, uma vez que em áreas onde houve a degradação do ecossistema florestal para a introdução de pastagens ou para cultivo, ocorre um domínio de espécies invasoras herbáceas, gramíneas e arbustos (ARAUJO et al., 2001). Um fator de influência na riqueza de espécies do banco de semente é o tempo em que ocorre a dispersão e o recrutamento de plântulas. Em estudos realizados em área de domínio ciliar, Gasparino et al. (2006) identificaram 37 famílias e 81 espécies. Das espécies identificadas, 65,4\% foram consideradas como invasoras, $7,41 \%$ como gramíneas e $27,19 \%$ como arbóreas. Dentre as espécies arbóreas, foram identificadas 19 famílias com Ulmaceae, Cecropiaceae e Euphorbiaceae, apresentando-se com maior número de plântulas e em amostras de áreas com remanescentes florestais. Gonçalves et al. (2011) observaram a predominância de espécies herbáceas (80\%), seguida da arbustiva (16\%) e arbórea (4\%) em área de Caatinga invadida por Parkinsonia aculeata L.

As sementes de espécies herbáceas espontâneas têm a função de iniciar o processo de sucessão desde os primeiros estágios de colonização em áreas perturbadas (ARAÚJO et al., 2004). Quanto às espécies arbóreas, Gonçalves et al. (2011) ressaltam que essas espécies produzem propágulos com intenso mecanismo de dormência, impedindo a sua germinação ou pelos diásporos germinarem logo após a dispersão. Em bancos de sementes na Caatinga, ocorrem variações sazonais e interanuais na riqueza de espécies que são influenciadas pela irregularidade das chuvas, onde reduções nos totais pluviométricos entre anos podem reduzir a riqueza do banco de sementes, porém o efeito só pode ser visível em anos subsequentes, uma vez que o ano mais chuvoso e que exibiu menor riqueza de espécies, foi antecedido por um ano de baixa disponibilidade hídrica (SILVA, 2009).

\section{Densidade do banco de sementes do solo}

A densidade média do banco de sementes da área de estudo foi de 2.942 sementes.m $^{-2}$ (lagoa) e 3.826 sementes. $\mathrm{m}^{-2}$ (no entorno) e após o estresse hídrico foi de 732 sementes. $\mathrm{m}^{-2}$ e 1.208 sementes. $\mathrm{m}^{-2}$, nas áreas da lagoa e do seu entorno, respectivamente. Comparando-se a densidade de sementes $/ \mathrm{m}^{2} / \mathrm{mês}$ na área experimental, observou-se que houve diferenças significativas pelo teste do $\mathrm{X}^{2}$ (Qui-Quadrado) $(\mathrm{p}<0,05)$ entre as áreas da lagoa e do entorno, com exceção dos meses de maio e pós-estresse hídrico (Figura 3).

Em regiões semiáridas, empregando o método de emergência de plântulas, Costa e Araújo (2003) e Mamede e Araújo (2008) observaram densidade de sementes variando de 807 a 2.642 sementes. $\mathrm{m}^{-2}$. A intensidade, duração do período chuvoso e a redução da disponibilidade hídrica em florestas tropicais secas influenciaram diretamente tanto na densidade de sementes no banco, quanto na formação do banco, principalmente por espécies anuais, estando o número de sementes sujeito à variação sazonal e interanual (FACELLI; CHESSON; BARNES, 2005). 
Figura 3 - Densidade mensal do banco de sementes do solo expressa em sementes.m ${ }^{2}$

Figure 3 - Monthly density of the soil seed bank expressed in seeds. $\mathrm{m}^{-2}$

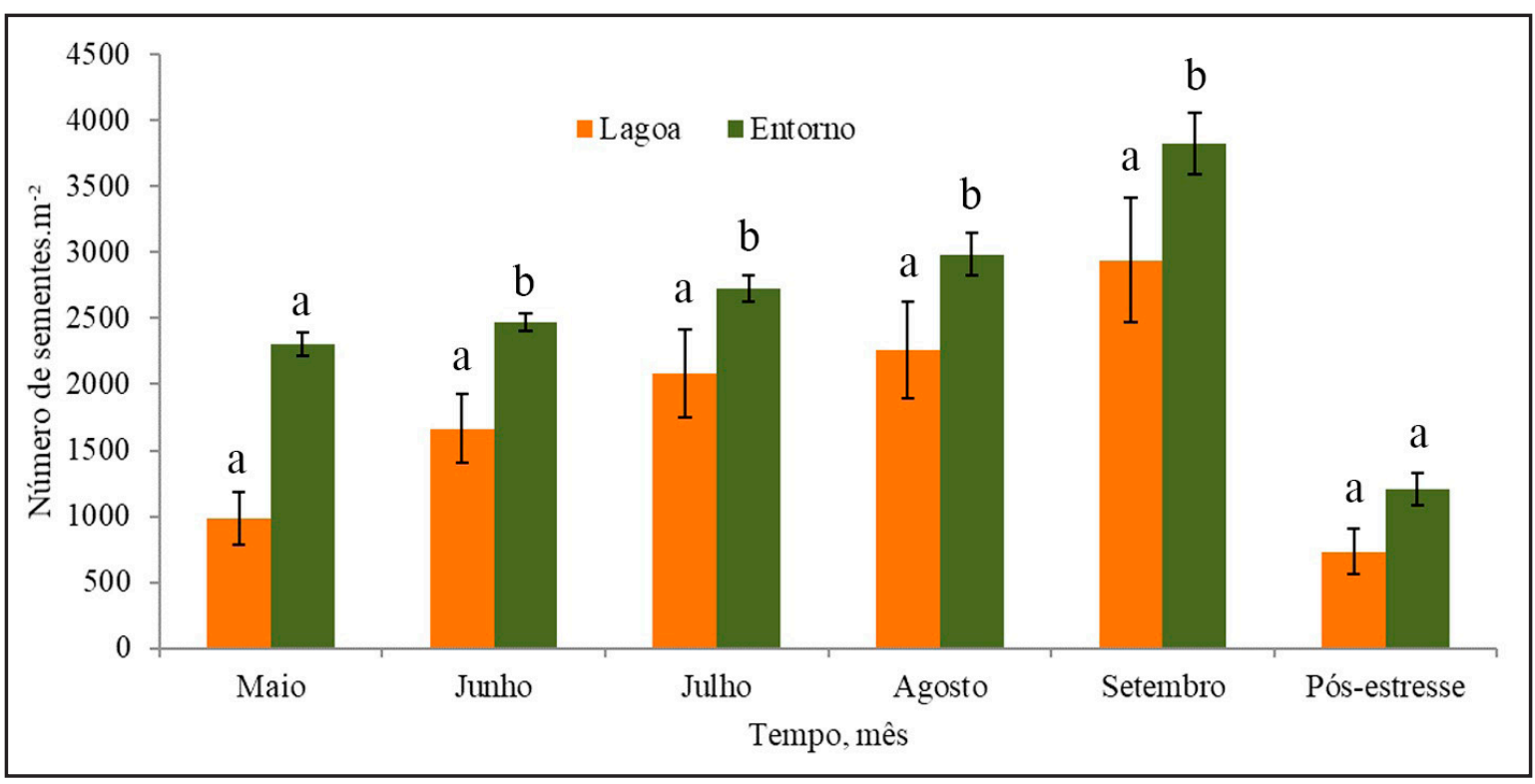

Fonte: Autores (2019)

O número de plântulas e a composição do banco de sementes do solo em áreas de mata ciliar foi avaliado por Gasparino et al. (2006) da seguinte forma: 551,68 sementes. $\mathrm{m}^{-2}$ em áreas de remanescentes florestais, 451,36 sementes. $\mathrm{m}^{-2}$ na área de agricultura e 452,48 sementes. $\mathrm{m}^{-2}$ na área do pasto. Na mata ciliar da Caatinga, foi encontrada maior riqueza de espécies e grande número de espécies exclusivas, possivelmente devido à maior disponibilidade de água durante o tempo e a formação de dossel pelas espécies arbóreas comparado a outros micro-habitats (SANTOS et al., 2010).

Ao analisarem o banco de sementes do solo em áreas de Caatinga em Várzea - PB, Ferreira et al., (2014) observaram um total de 8.978 sementes germinadas, sendo 5.059 no solo (camada de $0-5 \mathrm{~cm}$ ) e 3.919 na serapilheira. Na área de Pasto Nativo germinaram 4.753 sementes, sendo este o maior número em relação às demais áreas analisadas: Estágio Avançado de Regeneração Natural (1.904 sementes germinadas), Estágio Inicial de Regeneração Natural (1.565 sementes germinadas) e Estágio Médio de Regeneração Natural (756 sementes germinadas).

Numa área de floresta de Caatinga em Caruaru-PE, Santos et al. (2016) analisaram por quatro anos o banco de sementes do solo em floresta jovem e madura, além da variação do banco de sementes de acordo com as estações do ano. Nesse estudo, encontraram 4.097 sementes. $\mathrm{m}^{-2}$ no banco de sementes do solo, sendo 1.594 sementes. $\mathrm{m}^{-2}$ na floresta jovem e 2.503 sementes. $\mathrm{m}^{-2}$ na floresta madura. Em relação às estações do ano, na estação chuvosa encontraram 460 sementes. ${ }^{-2}$ na floresta jovem e 854 sementes. $\mathrm{m}^{-2}$ na floresta madura. Além disso, observaram na estação seca a maior densidade média de sementes germinadas com 1.133 sementes. $\mathrm{m}^{-2}$ na floresta jovem e 1.649 sementes. $\mathrm{m}^{-2}$ na floresta madura.

\section{Isolinhas da Densidade do Banco de Sementes}

$\mathrm{Na}$ construção das isolinhas, foram levadas em consideração as repetições em cada ponto cardeal. Assim, correspondem ao somatório de todas as linhas, em que a mesma coloração na escala equivale ao valor total de sementes. $\mathrm{m}^{-2}$. A densidade do banco de sementes aos 52 dias do início do experimento (primeira contagem, da germinação até o florescimento das espécies, 
(Figura 4a) somando todos os pontos cardeais foi de 986 sementes. $\mathrm{m}^{-2}$ na área da lagoa temporária, sendo que o sentido Leste que apresentou maior densidade com 459 sementes. $\mathrm{m}^{-2}$ e no sentido Norte não houve emergência de plântulas. $\mathrm{Na}$ área correspondente ao seu entorno, a densidade do banco foi 2.381 sementes. $\mathrm{m}^{-2}$, nos sentidos Leste e Sul apresentaram a mesma densidade com 655 sementes. $\mathrm{m}^{-2}$.

Aos 83 dias após o início do experimento (segunda contagem, Figura 4b) a densidade do banco de sementes na área da lagoa teve um acréscimo de 680 sementes.m ${ }^{-2}$, com 272 sementes. ${ }^{-2}$ na posição Oeste, 230 sementes. $\mathrm{m}^{-2}$ na posição Sul, 161 sementes.m $^{-2}$ na posição Leste e 17 sementes.m ${ }^{-2}$ na posição Norte. Na área do entorno, teve aumento de 170 sementes.m ${ }^{-2}$, em comparação a densidade da contagem anterior. Destas, os sentidos Oeste e Norte apresentaram a mesma densidade com 68 sementes. $\mathrm{m}^{-2}$ e os sentidos Leste e Sul com 17 sementes. $\mathrm{m}^{-2}$.

\section{Figura 4 - Densidade do banco de sementes do solo (a) Primeira contagem; (b) Segunda contagem}

Figure 4 - Soil seed bank density (a) First count; (b) Second count

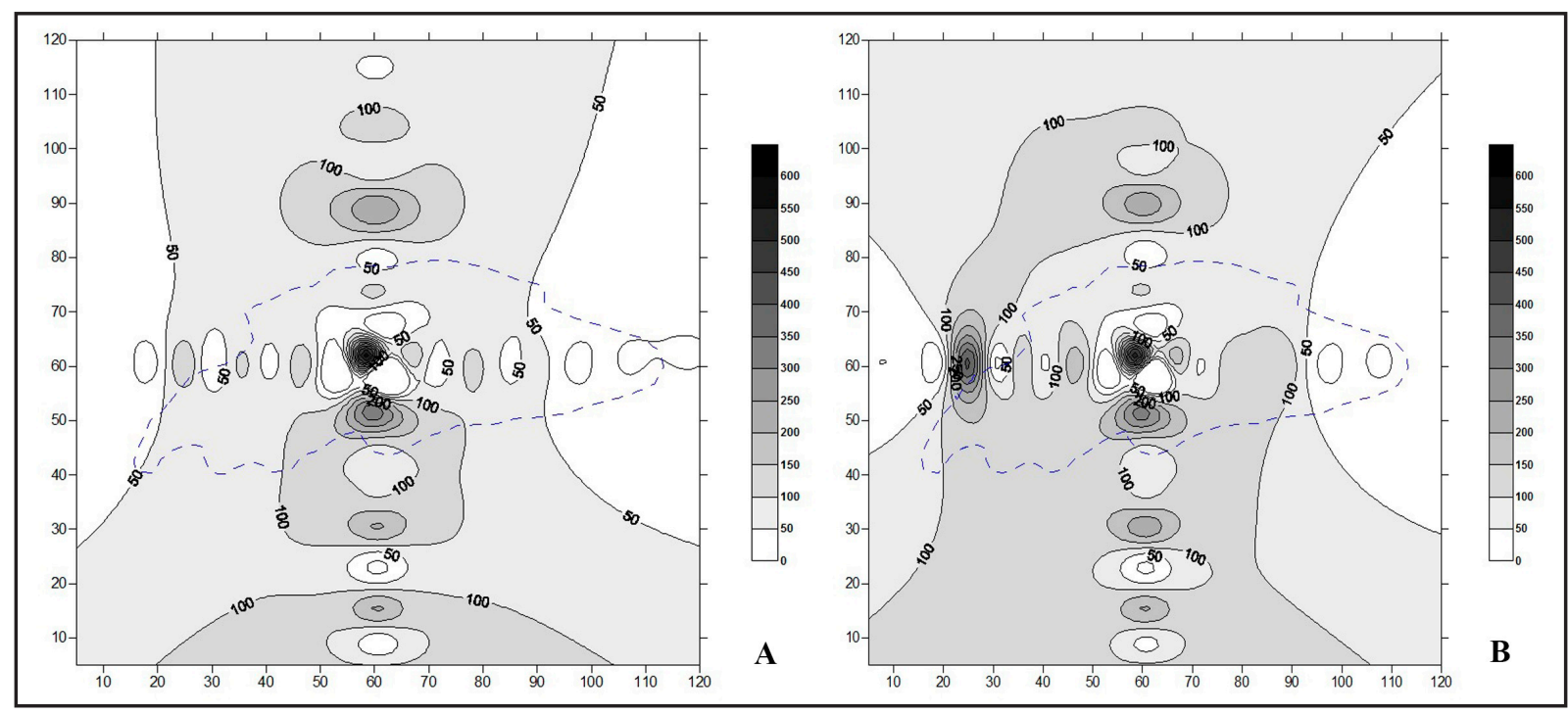

Fonte: Autores (2019)

$\mathrm{Na}$ área da lagoa, a densidade do banco de sementes aos 113 dias do início do experimento (terceira contagem, Figura 5a) aumentou em 417 sementes.m ${ }^{-2}$. Houve acréscimo 238 sementes.m ${ }^{-2}$ no sentido Oeste, 162 sementes. $\mathrm{m}^{-2}$ no Leste e 17 sementes. $\mathrm{m}^{-2}$ no Norte. No sentido sul, não foi observado aumento da densidade em relação à contagem anterior. Além disso, no entorno da lagoa temporária observou-se acréscimo de 255 sementes. $\mathrm{m}^{-2}$ : no sentido Leste 110 sementes. $\mathrm{m}^{-2}$, Oeste 76 sementes. $\mathrm{m}^{-2}$, Sul 43 sementes. $\mathrm{m}^{-2}$ e Norte com 26 sementes.m ${ }^{-2}$.

$\mathrm{Na}$ quarta contagem (144 dias após o início do experimento, Figura 5b) foram observadas na área da lagoa 179 sementes. $\mathrm{m}^{-2}$, sendo 85 sementes. $\mathrm{m}^{-2}$ no sentido Sul, 77 sementes. $\mathrm{m}^{-2}$ no Leste e 17 sementes. $\mathrm{m}^{-2}$ no Oeste. Não houve aumento da densidade do banco de sementes no sentido Norte. Na área do entorno, a densidade foi de 255 sementes. $\mathrm{m}^{-2}$ em comparação com a terceira contagem. Nos pontos cardeais, a densidade observada foi 196 sementes. $\mathrm{m}^{-2} \mathrm{em}$ Oeste, 25 sementes. $\mathrm{m}^{-2}$ no Norte e 17 sementes. $\mathrm{m}^{-2}$ nos sentidos Norte e Sul.

Aos 175 dias após o início do experimento (quinta contagem, Figura 6a), a densidade do banco de sementes aumentou em 680 sementes. $\mathrm{m}^{-2}$ na área da lagoa. Observou-se 315 sementes. $\mathrm{m}^{-2}$ no sentido Leste, 230 sementes. $\mathrm{m}^{-2}$ no Sul, 127 sementes. $\mathrm{m}^{-2}$ no Oeste e 8 sementes. $\mathrm{m}^{-2}$ no Norte. No seu entorno, a densidade foi 842 sementes. $\mathrm{m}^{-2}$ quando comparada a contagem anterior. Nos 
sentidos Leste e Oeste a densidade foi 272 sementes. $\mathrm{m}^{-2}$ cada um, de 179 sementes. $\mathrm{m}^{-2}$ no Sul e 119 sementes. $\mathrm{m}^{-2}$ no Norte.

\section{Figura 5 - Densidade do banco de sementes do solo (a) Terceira contagem;(b) Quarta contagem}

Figure 5 - Soil seed bank density (a)Third count; (b) Fourth count

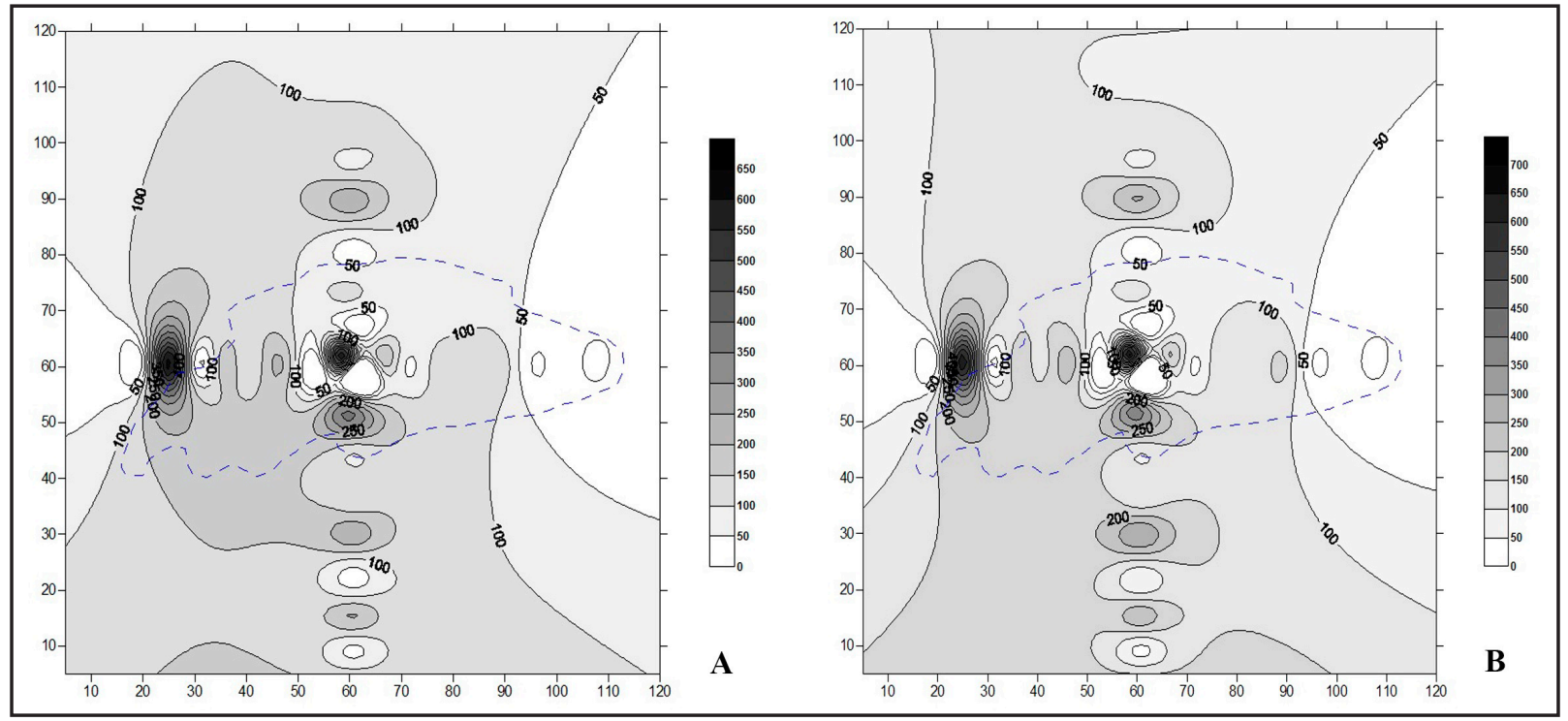

Fonte: Autores (2019)

Após o estresse hídrico, das 732 sementes. $\mathrm{m}^{-2}$ contabilizadas na área da lagoa (última contagem, Figura 6b), a densidade do sentido Sul foi 400 sementes. $\mathrm{m}^{-2}, 230$ sementes. $\mathrm{m}^{-2}$ no Leste, 102 sementes. $\mathrm{m}^{-2}$ no Oeste e nenhuma plântula foi observada no sentido Norte. Na área do entorno, das 1207 sementes. $\mathrm{m}^{-2}$ observadas, 442 sementes. $\mathrm{m}^{-2}$ foi no sentido Oeste, 357 sementes. $\mathrm{m}^{-2}$ no Leste, 212 sementes. $\mathrm{m}^{-2}$ no Sul e 196 sementes.m ${ }^{-2}$ no Norte.

Comparando as áreas da lagoa temporária e do seu entorno, é possível constatar que as diferenças nas áreas influenciam na densidade do banco de sementes do solo. Provavelmente, algumas sementes da área da lagoa se tornam inviáveis devido ao alagamento temporário e durante o escoamento superficial ocorrente no ponto cardeal Norte. O vento e a precipitação também proporcionam variações espaciais no banco de sementes do solo. O período de emergência de plântulas em áreas de Caatinga ocorre na estação chuvosa, (ARAÚJO et al., 2005; ARAÚJO; CASTRO; ALBUQUERQUE, 2007), como também nas chuvas eventuais (pulsos de precipitação) durante a estação seca, facilitando a germinação das sementes e influenciando na dinâmica do banco do solo. Em alguns casos, as plântulas recrutadas na estação seca têm baixa chance de sobrevivência, podendo ocorrer mortalidade antes da fase reprodutiva (ARAÚJO et al., 2005; ARAÚJO; CASTRO, ALBUQUERQUE, 2007; SILVA, 2009) e comprometer a reposição das sementes no banco.

Poucos estudos relacionam a densidade de sementes do solo e os pontos cardeais. Dentre eles, destaca-se o estudo realizado por Silva (2010) com três espécies florestais da Caatinga. Foi observado em Amburana cearensis (Allemão) A.C.Sm. (Fabaceae), Myracrodruon urundeuva Allemão (Anacardiaceae) e Handroanthus impetiginosus (Mart. ex. DC) Mattos (Bignoniaceae) que houve distribuição variável no número de sementes em relação aos pontos cardeais. Na serapilheira coletada em matrizes de $A$. cearensis foram encontradas 97 sementes viáveis, com dispersão predominante ao Norte $(42,27 \%)$ da árvore matriz, em $M$. urundeuva das 1.884 sementeshouve 
predominância do sentido Oeste $(36,24 \%)$ da árvore matriz e $H$. impetiginosa com 141 sementes viáveis com predominância ao Norte da árvore matriz (31,21\%).

\section{Figura 6 - Densidade do banco de sementes do solo (a) Quinta contagem; (b) Após estresse hídrico}

Figure 6 - Soil seed bank density (a) Fifth count; (b) After water stress

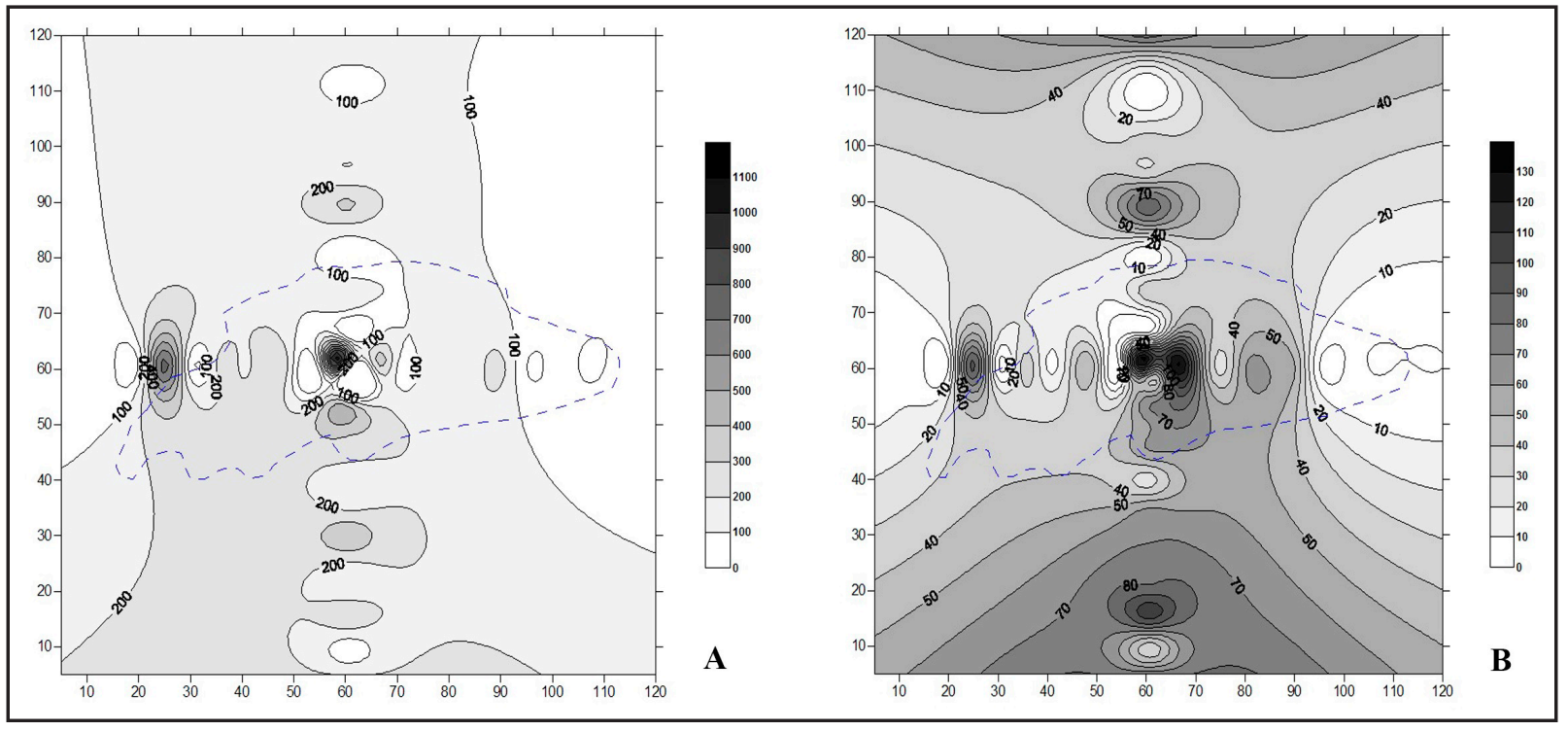

Fonte: Autores (2019)

Um dos fatores que influenciam na composição da densidade do banco de sementes do solo é o vento. As sementes podem ser perdidas por diferentes tipos de perturbações no ambiente (incêndios ou alagamentos) e pela pré-dispersão, através de agentes bióticos ou abióticos (vento, gravidade, chuva e animais). Assim, as sementes podem permanecer inativas no solo por longos períodos de tempo até que as condições ambientais estejam favoráveis para a germinação. Por outro lado, as sementes podem ser movidas por animais na direção oposta ou serem trazidas para a superfície do solo por meio do vento ou escoamento superficial (BOCHET, 2015).

Ao analisarem a densidade de sementes do solo em área de deserto, Jia et al. (2017) observaram que não houve diferenças significativas quanto à densidade de sementes em relação às posições geomórficas examinadas. No entanto, ainda segundo os autores, as posições geomórficas contribuíram significativamente para as diferenças na riqueza das espécies, diversidade e distribuição no solo, com maior densidade do banco de sementes na camada $0-2 \mathrm{~cm}$ do solo, sugerindo que a restauração e restabelecimento da vegetação pode ser implementada através da adição de sementes as camadas superficiais do solo.

\section{Conclusão}

O banco de sementes do solo da Caatinga foi representado em número de espécies pelas famílias Poaceae e Asteraceae e a forma de vida predominante foi o estrato herbáceo. Quanto à densidade de sementes. $\mathrm{m}^{-2}$, a maior foi na área do entorno da lagoa temporária e o ponto cardeal no sentido Norte em ambas as áreas apresentou menor densidade de sementes. $\mathrm{m}^{-2}$. 


\section{Agradecimentos}

À CAPES (Coordenação de Aperfeiçoamento de Pessoal de Nível Superior) pelo apoio financeiro, possibilitando a realização deste trabalho.

\section{Referências}

ARAÚJO, E. L.; CASTRO, C. C.; ALBUQUERQUE, U. P. Dynamics of Brazilian Caatinga - a review concerning the plants, environment and people. Functional Ecosystems and Communities, United Kingdom, v. 1, n. 1, p. 15-28, abr. 2007.

ARAÚJO, E. L. et al. Diversidade de herbáceas em microhabitats rochoso, plano e ciliar em uma área de Caatinga, Caruaru-PE. Acta Botânica Brasílica, Belo Horizonte, v. 19, n. 2, p. 285-294, 2005.

ARAÚJO, M. M. et al. Caracterização da chuva de sementes, banco de sementes do solo e banco de plântulas em floresta estacional decidual ripária, Cachoeira do Sul, RS, Brasil. Scientia Forestalis, Piracicaba, n.66, p. 128-141, dez. 2004.

ARAUJO, M. M. et al. Densidade e composição florística do banco de sementes do solo de florestas sucessionais na região do Baixo Rio Guamá, Amazônia Oriental. Scientia Forestalis, Piracicaba, v. 59, n. 1, p. 115-130, jun. 2001.

BASKIN, J. M.; NAN, X.; BASKIN, C. C.A comparative study of seed dormancy and germination in an annual and a perennial species of Senna (Fabaceae). Seed Science Research, Cambrigde, v.8, p. 501-512, 1998.

BOCHET, E. The fate of seeds in the soil: a review of the influence of overland flow on seed removal and its consequences for the vegetation of arid and semiarid patchy ecosystems. Soil, Munich, v. 1, p. 131-146, jan. 2015.

COSTA, R. C.; ARAUJO, F. S. Densidade, germinação e flora do banco de sementes no solo, no final da estação seca, em uma área de caatinga, Quixadá, CE. Acta Botânica Brasilica, Belo Horizonte, v. 17, n. 2, p. 259-264, 2003.

FACELLI, J. M.; CHESSON, P. BARNES, N.Differences in seed biology of annual plants in arid lands: a key ingredient of the storage effect. Ecology, Califórnia, v. 86, n. 11, p. 2998-3006, nov. 2005.

FERREIRA, C. D. etal. Florística do banco de sementes no solo em diferentes estágios de regeneração natural de Caatinga. Revista Brasileira de Ciências Agrárias, Recife, v. 9, n. 4, p. 562-569, 2014.

FIGLIOLIA, M. B.; FRANCO, G. A. D. C.; BIRUEL, R. P. Banco de sementes do solo e potencial de regeneração de área ripárea alterada, em Paraguaçu Paulista, SP. In: VILLAS BÔAS, O.; DURIGAN, G. (org.). Pesquisas em conservação e recuperação ambiental no Oeste Paulista: resultados da cooperação Brasil/Japão. São Paulo: Instituto Florestal, 2004. p. 181-197.

FIGUEROA, J. A.; TEILLIER, S.; JAKSIC, F. M. Composition, size and dynamics of the seed bank in a mediterranean shrubland of Chile. Austral Ecology,Australia,v. 29, p. 574-584, 2004.

JARDIM BOTÂNICO DO RIO DE JANEIRO. Flora do brasil 2020 em construção. Rio de Janeiro, [2020]. Disponível em: http://floradobrasil.jbrj.gov.br/. Acesso em: 30 nov. 2019.

GASPARINO, D. et al. Quantificação do banco de sementes sob diferentes usos do solo em área de domínio ciliar. Revista Árvore, Viçosa, MG, v. 30, n. 1, p. 1-9, 2006.

GONÇALVES, G. S. et al. Estudo do banco de sementes do solo em uma área de caatinga invadida por Parkinsonia aculeata L. Revista Brasileira de Biociências, Porto Alegre, v. 9, n. 4, p. 428-436, 2011. 
GUO, Q.; RUNDEL, P. W.; GOODALL, D. W. Horizontal and vertical distribution of desert seed banks: patterns, causes, and implications. Journal of Arid Environments, Lincoln, v. 38, n. 3, p. 465-478,1998.

JIA, F. et al. Characteristics of soil seed banks at different geomorphic positions within the longitudinal sand dunes of the Gurbantunggut Desert, China. Journal of Arid Land, China, v. 9, n. 3, p. 355-367, mar. 2017.

KELLERMAN, M. J. S.; VAN ROOYEN, M. W. Seasonal variation in soil seed bank size and species composition of selected habitat types in Maputaland, South Africa. Bothalia, South Africa,v.37, n. 2, p. 249-258, ago. 2007.

MAMEDE, M. A.; ARAÚJO, F. S.Effects of slash and burn practices on a soil seed bank of Caatinga vegetation in Northeastern Brazil. Journal of Arid Environments, Lincoln, v.72, p. 458-470, abr. 2008 .

PARENTE, R. G. et al. Composição florística do banco de sementes do solo da caatinga em perímetro irrigado de Petrolina - Pernambuco. Revista Semiárido de Visu, Petrolina, v. 1, n. 1, p. 18-31, 2011.

RIBEIRO, T. O. et al. Diversidade do banco de sementes em diferentes áreas de caatinga manejadas no semiárido da Paraíba, Brasil. Ciência Florestal, Santa Maria, v. 27, n. 1, p. 203-213, jan./mar. 2017.

RODAL, M. J. N.; SAMPAIO, E. V. S. B.; FIGUEREDO, M. A. Manual sobre método de estudo florístico e fitossociológico: ecossistema caatinga. Brasília: Sociedade Botânica do Brasil,2013. 24 p.

SAATKAMP, A.; POSCHLOD, P.; VENABLE, D. L. The functional role of soil seed banks in natural communities. In: GALLAGHER, R. S. (ed.). Seeds: the ecology of regeneration in plant communities. 3rd ed. London: CABI, 2014. p. 263-295.

SANTOS, D. M. et al. Can spatial variation and inter-annual variation in precipitation explain the seed density and species richness of the germinable soil seed bank in a tropical dry forest in northeastern Brazil? Flora, Netherlands, v. 208, p. 445-452, jul. 2013.

SANTOS, D. M. et al. Composition, species richness, and density of the germinable seed bank over 4 years in young and mature forests in Brazilian semiarid regions. Journal of Arid Environments, Lincoln (USA), v. 129, p. 93 - 101, fev. 2016.

SANTOS, D. M. et al. Variação espaço-temporal do banco de sementes em uma área de Floresta Tropical Seca (Caatinga) - Pernambuco. Revista de Geografia, Recife, v. 27, n. 1, p. 234-253, abr. 2010.

SILVA, J. E. R. Estudo da dispersão de sementes, banco de sementes e regeneração natural de três espécies arbóreas da caatinga. 2010. Monografia (Graduação em Engenharia Florestal) - Universidade Federal de Campina Grande, Unidade Acadêmica de Engenharia Florestal, Patos, 2010.

SILVA, K. A. Banco de sementes (lenhosas e herbáceas) e dinâmica de populações herbáceas em uma área de Caatinga em Pernambuco. 2009. Tese (Doutorado em Botânica) - Universidade Federal Rural de Pernambuco, Recife, 2009.

SOUSA, F. Q. et al. Banco de sementes do solo de caatinga invadida por Cryptostegia madagascariensis Bojer ex Decne. Revista Brasileira de Ciências Agrárias, Recife, v. 12, n. 2, p. 220-226, abr. 2017.

SUPERINTENDÊNCIA DE ADMINISTRAÇÃO DO MEIO AMBIENTE. Atualização do Diagnóstico florestal do Estado da Paraíba. João Pessoa: SEDEMA, 2004. 268 p.

WALCK, J. L. et al. Defining transient and persistent seed banks in species with pronounced seasonal dormancy and germination patterns. Seed Science Research, England, v. 15, p. 189-196, 2005. 